\title{
Preventing Anal Sphincter Tears During Delivery. An Update from Scandinavia
}

\author{
Jouko Pirhonen* \\ University Hospital of North Norway, Norway
}

*Corresponding author: Jouko Pirhonen, Norwegian Continence and Pelvic Floor Center, University Hospital of North Norway, Norway.

Received Date: November 13, 2018

Published Date: November 26, 2018

\section{Editorial}

A common outcome of vaginal delivery is perineal trauma. The most serious among these injuries are third- and fourthdegree lacerations or obstetric anal sphincter injuries. Studies have reported that $30-50 \%$ of women with these lacerations experience anal incontinence. Symptoms of anal incontinence may affect a woman's social, psychological, and sexual life; moreover, a previous anal sphincter injury can increase the risk of recurrence in subsequent deliveries. Therefore, it is important to prevent these injuries.

The frequency of anal sphincter injuries varies a lot between countries in Europe. The highest rates are being reported from Switzerland, Iceland, Sweden and Denmark, and a frequency counting to $6 \%$ of all vaginal deliveries is reported. The lowest rates are usually found in Eastern Europe, Israel, Italy, and Finland where the tear rates have been below $1 \%$ but even close to $0.5 \%$.

In Scandinavia, a first alarming report came out already 1998 [1], showing the frequency of serious tears $0.37 \%$ in Finland compared to $2.7 \%$ in Sweden. However, there was no change in the development of tear frequency. It took several years before the clinical practice began to change. In 2005 the central authorities in Norway finally decided to do something to stop this devastating process. After an intervention in five hospitals throughout Norway, a dramatic decrease in the frequency of anal sphincter injuries was noticed [2-4]. After a time of 13 years, this positive change still exists. Before the intervention, Norway had a rate of serious tears of $4.3 \%$, and today they stay at $1.8 \%$.

This important project was followed by a similar project in Denmark and Iceland, and positive effects were obvious. The main challenge in these two countries still is how to go further. Unfortunately, there does not exist a solid sphincter team who could continue the promising work started by foreign experts. It is far easier to continue a well-known familiar practice than make any changes. In contrast to other countries there is even a typical
Danish phenomenon where a group of prominent physicians are completely against the change seen in nearby countries denying comparing statistics between different countries.

Today the focus in Scandinavia is in Sweden. Many promising results are today available and getting closer to the results at the best clinics in Finland [5].

We still have a long way to go. A change will take long time as well as a change in clinical practice does. Some new reports make the work much easier. Recently, we published an article from Varberg in Sweden, where the local clinic tried to change two things at the same time, i.e. to decrease the number of serious tears and decrease the increased rate of cesarean sections. Many positive signs can be read in this article. In addition, we have received important reports from Netherlands showing a clear association between episiotomy and grade three and four tears in instrumental deliveries [6].

\section{Acknowledgement}

None.

\section{Conflict of Interest}

No Conflict of Interest.

\section{References}

1. Pirhonen JP, Grenman SE, Haadem K, Gudmundsson S, Lindqvist P, et al. (1998) Frequency of anal sphincter rupture at delivery in Sweden and Finland--result of difference in manual help to the baby's head. Acta Obstet Gynecol Scand 77(10): 974-977.

2. Laine K, Pirhonen T, Rolland R, Pirhonen J (2008) Decreasing the incidence of anal sphincter tears during delivery. Obstet Gynecol 111(5): 1053-1057.

3. Hals E, Oian P, Pirhonen T, Gissler M, Hjelle S, et al. (2010) A multicenter interventional program to reduce the incidence of anal sphincter tears. Obstet Gynecol 116(4): 901-908.

4. Pirhonen T, Gissler M, Hartgill T, Pirhonen J (2011) Experiences of expert midwives in a training program aimed at decreasing perineal tears. Int $\mathrm{J}$ Nurs Midwifery 3(6): 70-75. 
5. Pirhonen J, Samuelsson E, Pirhonen T, Odeback A, Gissler M (2018) Interventional program to reduce both the incidence of anal sphincter tears and rate of caesarean sections. Eur J Obstet Gynecol Reprod Biol 223: 56-59.
6. van Bavel J, Hukkelhoven CWPM, de Vries C, Papatsonis DNM, de Vogel J, et al. (2018) The effectiveness of mediolateral episiotomy in preventing obstetric anal sphincter injuries during operative vaginal delivery: a tenyear analysis of a national registry. Int Urogynecol J 29: 407-413. 